\title{
Structural and functional characterisation of new-onset idiopathic dilated cardiomyopathy, and its response to therapy
}

\author{
Darryl P Leong*1, Nicholas Shipp ${ }^{1}$, Adhiraj Chakrabarty2 ${ }^{2}$ Lucas Joerg3, \\ Mitra Shirazi ${ }^{3}$, Payman Molaee ${ }^{1}$, Rebecca Perry ${ }^{3}$, Amy Penhall ${ }^{3}$, \\ Carmine G De Pasquale ${ }^{2}$ and Joseph B Selvanayagam ${ }^{2}$
}

\author{
Address: ${ }^{1}$ University of Adelaide, Adelaide, Australia, ${ }^{2}$ Flinders University, Bedford Park, Australia and ${ }^{3}$ Flinders Medical Centre, Bedford Park, \\ Australia \\ * Corresponding author
}

from 13th Annual SCMR Scientific Sessions

Phoenix, AZ, USA. 21-24 January 2010

Published: 21 January 2010

Journal of Cardiovascular Magnetic Resonance 2010, I2(SuppI I):PI84 doi:I0.I I86/I532-429X-I2-SI-PI84

This abstract is available from: http://jcmr-online.com/content/I2/SI/PI84

(c) 2010 Leong et al; licensee BioMed Central Ltd.

\section{Introduction}

The prevalence of myocardial fibrosis among patients with idiopathic dilated cardiomyopathy (IDCM), as detected by the late-gadolinium cardiac magnetic resonance (LG-CMR) technique, is reported to be $28-42 \%$ in highly-selected samples from specialist heart failure clinics. The presence of fibrosis has been demonstrated to predict the incidence of major adverse cardiovascular events. However, as the heart failure duration prior to first CMR imaging in these studies was at least 12 months the prevalence of myocardial fibrosis at presentation is unknown. Moreover, the determinants of the response-to-therapy of newly diagnosed IDCM patients have not been characterised using CMR and advanced echocardiographic techniques.

\section{Purpose}

1. To determine the prevalence of myocardial fibrosis using the LG-CMR technique among newly diagnosed idiopathic dilated cardiomyopathy IDCM patients presenting to a tertiary hospital setting. 2.To characterise cardiac remodelling and functional changes following medical therapy for IDCM.

\section{Methods}

Forty-five consecutive patients were studied, a median of 14 days (inter-quartile range 7-23 days) and 30 weeks (2233 weeks) after newly diagnosed IDCM. Coronary disease was excluded by angiography. All subjects underwent cine CMR for global and regional systolic functional assessment, T2-weighted inversion-recovery sequences for myocardial oedema (to exclude myocarditis) and LG-CMR for assessment of myocardial fibrosis. Additionally, subjects underwent echocardiography for evaluation of LV diastolic function and dyssynchrony (as measured by the radial and longitudinal strain dyssynchrony indices). Functional assessment was undertaken using cardiopulmonary exercise testing, 6-minute walk test, and Minnesota Living With Heart Failure Questionnaire.

\section{Results}

Late-gadolinium enhancement was present in eight $(18 \%)$ subjects at presentation. There was significant improvement in LV and RV systolic function, LV remodelling, LV diastolic function, left atrial function and remodelling following therapy (Table 1). Advancing age was the only predictor of poor response in LV systolic function with therapy $\left(r^{2}=0.22, p=0.04\right)$, whereas late-gadolinium enhancement, LV eccentricity, and $\mathrm{VO}_{2} \operatorname{MAX}$ did not. The more dyssynchronous the LV the greater the reduction in LV mass following medical therapy (longitudinal strain dyssynchrony index: $\mathrm{r}^{2}=0.28, \mathrm{p}=0.02$; radial strain dyssynchrony index $\mathrm{r}^{2}=0.32, \mathrm{p}=0.02$ ). 
Table I:

\begin{tabular}{|c|c|c|c|}
\hline Parameter & Baseline & Follow-up & P-value \\
\hline \multicolumn{4}{|l|}{ CMR } \\
\hline LV ejection fraction \pm SD (\%) & $27 \pm 9$ & $45 \pm 10$ & $<0.001$ \\
\hline LV end-systolic volume $\pm \mathrm{SD}(\mathrm{mL})$ & $120 \pm 42$ & $93 \pm 46$ & 0.004 \\
\hline LV end-diastolic volume $\pm \mathrm{SD}(\mathrm{mL})$ & $167 \pm 45$ & $155 \pm 53$ & 0.1 \\
\hline $\mathrm{LV}$ mass $\pm \mathrm{SD}(\mathrm{g})$ & $158 \pm 39$ & $147 \pm 34$ & 0.004 \\
\hline LV eccentricity index (LV mass/LVEDV) $\pm \mathrm{SD}(\mathrm{g} / \mathrm{mL})$ & $0.64 \pm 0.13$ & $0.76 \pm 0.17$ & 0.03 \\
\hline $\mathrm{RV}$ ejection fraction $\pm \mathrm{SD}(\%)$ & $46 \pm 15$ & $60 \pm 9$ & 0.004 \\
\hline $\mathrm{RV}$ end-diastolic volume $\pm \mathrm{SD}(\mathrm{mL})$ & $79 \pm 38$ & $60 \pm 32$ & 0.2 \\
\hline $\mathrm{RV}$ end-systolic volume $\pm \mathrm{SD}(\mathrm{mL})$ & $143 \pm 42$ & $140 \pm 47$ & 0.4 \\
\hline \multicolumn{4}{|l|}{ Echocardiographic } \\
\hline LA volume $\pm S D(m L)$ & $97 \pm 30$ & $73 \pm 26$ & 0.002 \\
\hline LA strain \pm SD (\%) & $12 \pm 6$ & $19 \pm 6$ & 0.02 \\
\hline E/A ratio & $1.4 \pm 0.9$ & $0.9 \pm 0.4$ & 0.04 \\
\hline Diastolic grade $\pm S D$ & $2.4 \pm 1.1$ & $1.3 \pm 0.8$ & 0.002 \\
\hline \multicolumn{4}{|l|}{ Functional } \\
\hline Heart rate \pm SD (bpm) & $80 \pm 17$ & $64 \pm 13$ & $<0.001$ \\
\hline $6-M W D \pm S D(m)$ & $421 \pm 103$ & $483 \pm 85$ & 0.07 \\
\hline $\mathrm{VO}_{2 \operatorname{MAX}} \pm \mathrm{SD}(\mathrm{mL} / \mathrm{kg} / \mathrm{min})$ & $20 \pm 5$ & $21 \pm 5$ & 0.7 \\
\hline MLWHF score & $40 \pm 19$ & $30 \pm 21$ & 0.13 \\
\hline
\end{tabular}

\section{Conclusion}

This study demonstrates for the first time a moderate prevalence of myocardial fibrosis at diagnosis of IDCM - less than in series of established IDCM. This may reflect delays to presentation owing to the insidious nature of symptoms. LV dyssynchrony portends favourable cardiac remodelling with pharmacotherapy, extending observations from cardiac resynchronisation literature.

Publish with Bio Med Central and every scientist can read your work free of charge

"BioMed Central will be the most significant development for disseminating the results of biomedical research in our lifetime. "

Sir Paul Nurse, Cancer Research UK

Your research papers will be:

- available free of charge to the entire biomedical community

- peer reviewed and published immediately upon acceptance

- cited in PubMed and archived on PubMed Central

- yours - you keep the copyright

Submit your manuscript here:

http://www.biomedcentral.com/info/publishing_adv.asp 